\title{
Acceptance of female urologists among patients with suspected prostate disease
}

\author{
Fabian Steinkohl ${ }^{1} \wedge$, Anna Katharina Luger ${ }^{2} \wedge$, Leonhard Gruber $^{2} \wedge$, Margarethe Hochleitner $^{3}$, \\ Renate Pichler ${ }^{4}$, Isabel Heidegger-Pircher ${ }^{4}$, Jasmin Bektic $^{4}$, Friedrich Aigner ${ }^{2}$
}

${ }^{1}$ Department of Radiology, St. Vincent Hospital, Zams, Austria; ${ }^{2}$ Department of Radiology, Innsbruck Medical University, Innsbruck, Austria; ${ }^{3}$ Department of Internal Medicine, Gender Medicine Unit, Innsbruck Medical University, Innsbruck, Austria; ${ }^{4}$ Department of Urology, Innsbruck Medical University, Innsbruck, Austria

Contributions: (I) Conception and design: All authors; (II) Administrative support: All authors; (III) Provision of study materials or patients: All authors; (IV) Collection and assembly of data: F Steinkohl, AK Luger; (V) Data analysis and interpretation: F Steinkohl, L Gruber; (VI) Manuscript writing: All authors; (VII) Final approval of manuscript: All authors.

Correspondence to: Anna Katharina Luger, MD. Department of Radiology, Innsbruck Medical University, Anichstraße 35, 6020 Innsbruck, Austria. Email: anna.luger@i-med.ac.at.

\begin{abstract}
Backgrounds: The number of practicing female urologists is rising. The aim of this study is to evaluate the acceptance of female urologists by male patients and their partners.

Methods: Men who underwent a prostate MRI or a prostate biopsy between January and December 2018 and their partners, were sent questionnaires prior to the examination. Two types of questionnaires were used. One questionnaire asked "I want to be seen by: (I) a male urologist or (II) a female urologist or (III) no preference" (Group ${ }_{n p}$ ), the other questionnaire only offered two possible answers: "I want to be seen by: (I) a male urologist or (II) a female urologist" $\left(\right.$ Group $\left._{\mathrm{m}, \mathrm{f}}\right)$. All other questions were on prostate MRI and prostate biopsies.

Results: Overall, 377 questionnaires were sent to patients. One hundred and ninety-six questionnaires (52.0\%) were returned. In Group ${ }_{n p}, 34.7 \%$ wanted to be seen by a male urologist, $60.8 \%$ of patients chose "no preference". The answers of the patients' female partners in Group ${ }_{n p}$ did not differ statistically significant ( $57.3 \%$ chose "no preference", $0 \%$ chose a female urologist). In Group $\mathrm{m}_{\mathrm{f}, \mathrm{f}}, 54.5 \%$ of patients preferred a male urologist, one patient wanted to be seen by a female urologist, $44.3 \%$ did not answer the question. In Group $\mathrm{m}_{\mathrm{f}}$, there was no statistically significant difference in preference in regard to the doctor's gender between the patients and their female partners $(57 \%$ of partners wanted a male urologist, $0 \%$ wanted a female urologist).
\end{abstract}

Conclusions: A large number of patients with prostate disease and their partners prefer male urologists rather than female urologists.

Keywords: Female urologist; prostate biopsy; gender; gender preferences; prostate cancer

Submitted Feb 10, 2021. Accepted for publication May 11, 2021.

doi: $10.21037 /$ tau-21-131

View this article at: https://dx.doi.org/10.21037/tau-21-131

^ ORCID: Fabian Steinkohl, 0000-0003-0055-2203; Anna Katharina Luger, 0000-0002-0445-8372; Leonhard Gruber, 0000-0003-3351-799X. 


\section{Introduction}

It has been nearly 120 years since women have had the right to become physicians in Germany. Female doctors were curiosity at the beginning of the $20^{\text {th }}$ century. Nowadays two thirds of first-year medical students in Germany are female (1). This trend is also observed in other parts of the world. While $36.4 \%$ of all junior doctors were female in 1998, this number increased to $48 \%$ in 2009 (2). In gynecology and obstetrics, the number of female applicants for training positions is estimated to be $84.2 \%$. This led authors to describe a "feminization" of medicine (3). In some areas of medicine female doctors are underrepresented. Only neurosurgery and orthopedics have fewer female doctors than urology according to a study published in 2015 (4).

It is known that the gender of the doctor influences patient satisfaction (5). It is therefore not surprising that patients have preferences for either female or male doctors. In the United Arab Emirates, $86.4 \%$ of patients wish for a female gynecologist (6). It was published in 1968 that the acceptance of female doctors was high, apart from the "unpopularity of female urologists" (7). A recent study found that male doctors receive more 'positive' and more 'very positive' evaluations regarding patient satisfaction and medical reputation by patients and medical peers compared to their female colleagues (8).

It is important to monitor the acceptance of female urologists among urologic patients for several reasons. The medical community might take results of lower acceptance of female urologists as an occasion to increase awareness of this problem. For a female urologist it might be important to know what level of acceptance she can currently expect prior to start working in private practice.

This study aims to verify whether the claimed "unpopularity of female urologists" is still true. To this end, this study assesses the acceptance of female urologists among patients with suspected prostate disease and their partners.

We present the following article in accordance with the SURGE reporting checklist (available at https://dx.doi. org/10.21037/tau-21-131).

\section{Methods}

The study was conducted in accordance with the Declaration of Helsinki (as revised in 2013). The study was approved by institutions local ethics committee Innsbruck Medical University (NO.: EK-Nr. 1162/2017).
Patients who underwent a prostate MRI or a prostate biopsy between January and December 2018 and their partners, were asked to participate in this single-center study.

Patients and their partners received a letter with a questionnaire shortly before the exam. There was a separate questionnaire for the patient and their partner, and they were asked to complete the questionnaires independently and return them to our department on the day of the examination. The answers obtained were anonymized and saved for statistical analysis. All patients gave their consent to their participation in the study. The questions were included in a questionnaire with questions on transrectal prostate ultrasound and prostate MRI. Two types of questionnaires were used, which differed only in the possible answers for the question on the preferred gender of the urologist. "I want to be seen by: (I) a male urologist or (II) a female urologist or (III) no preference" $\left(\right.$ Group $\left._{\text {np }}\right)$ and "I want to be seen by: (I) a male urologist or (II) a female urologist" (Group $\mathrm{p}_{\mathrm{m}, \mathrm{f}}$ ). The question for the partners was "I want my partner to be seen by: ...). The participants were randomly distributed to one of the two questionnaires.

\section{Statistical analysis}

All data were collected and stored in Microsoft Excel (RRID:SCR_016137 version 2016). Statistical analysis was carried out in GraphPad Prism (RRID:SCR_002798 version 8.1) and SPSS Statistics (RRID:SCR_019096 version 25.0).

$95 \%$ confidence intervals $(\mathrm{CI})$ are given in nonparametric variables and as mean \pm standard deviation $(\mathrm{SD})$ in those with a normal distribution. $\mathrm{P}$ values $<0.05$ were considered significant, adjustment for multiple testing was performed where appropriate.

Demographic parameters were compared between male participants with questionnaires type $\mathrm{A}$ and type $\mathrm{B}$ via an unpaired $t$-test for age and a $\chi^{2}$-test in case of education levels and religious affiliation as well as between participants and partners.

The distribution of answers was compared between men and partners as well as between men taking test types A or B via a $\chi^{2}$-test.

A binary regression analysis [5.000 samples, biascorrected accelerated (BCa) 95\% CIs] was carried out to test for the effect of questionnaire type, patient age, religious affiliation, educational level, presence and duration of marriage, retirement, prior biopsy, and prior MRI (used as a marker for previous contact with the urologic 

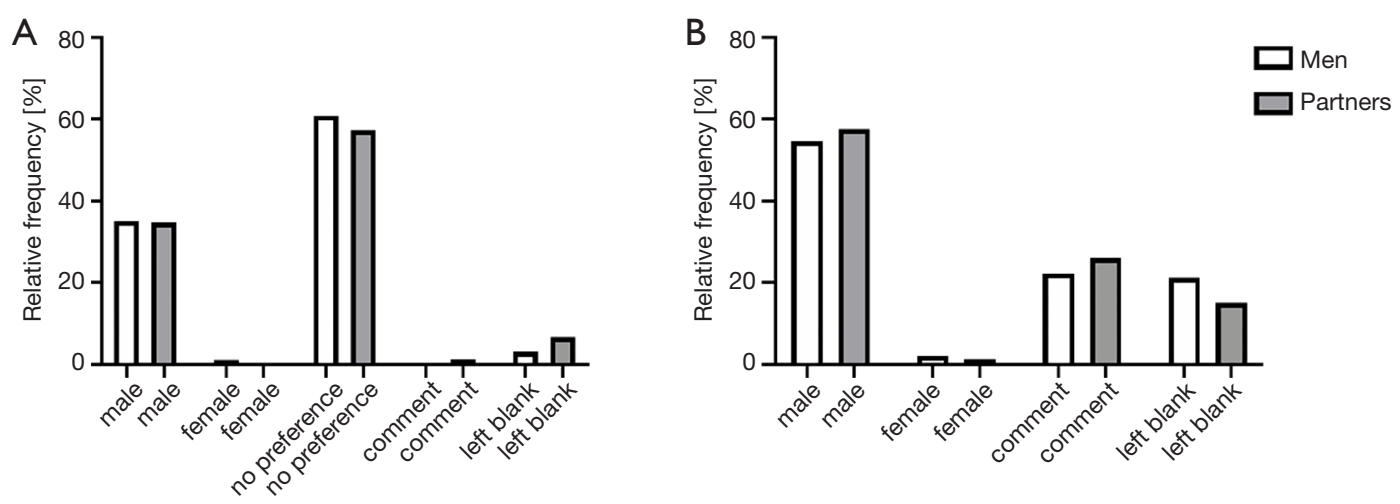

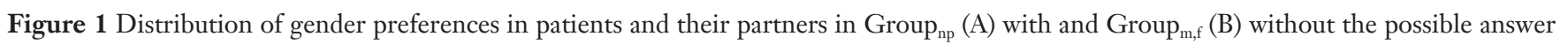
'no preference'.

profession) on a potential male preference. Results are given as unstandardized beta (B, i.e., correlation slope), $95 \%$ corresponding $\mathrm{CI}$, and $\mathrm{P}$ values. Factor collinearity was excluded via variance inflation factor analysis.

\section{Results}

\section{Questionnaire information}

Overall, 377 questionnaires were sent to patients. 196 questionnaires $(52.0 \%)$ were returned (Group : 97 , Group $\left._{\mathrm{m}, \mathrm{f}}: 99\right)$, among those 75 (Group ${ }_{\mathrm{np}}$ ) and 73 (Group $_{\mathrm{m}, \mathrm{f}}$ ), contained answers from partners. All respondents, whether partial or complete were included in analysis.

\section{Demographics}

The average age of participating men was $65.6 \pm 7.3$ years with participating partners-all of whom were femalebeing significantly younger at $62.7 \pm 8.4$ years on average $(\mathrm{P}=0.001)$.

There was no significant difference in regard to age in participating men $(65.6 \pm 7.1$ vs. $65.7 \pm 7.9$ years; $\mathrm{P}=0.977)$ nor partners (62.6 \pm 8.3 vs. $63.0 \pm 8.6$ years; $\mathrm{P}=0.770)$ regardless of questionnaire type $\left(G^{-}\right.$roup $_{\mathrm{np}}$ or Group $\mathrm{p}_{\mathrm{m}, \mathrm{f}}$ ). Education levels $(\mathrm{P}=0.124)$ and religious affiliation $(\mathrm{P}=0.213)$ in participating men did not differ either between tests.

\section{Urologist gender preference in patients and partners}

There was no significant difference in the distribution of answers between men and their partners, regardless of questionnaire type $\left[\mathrm{P}=0.506\left(\mathrm{Group}_{\mathrm{np}}\right)\right.$ and 0.735 $\left(\right.$ Group $\left._{\mathrm{m}, \mathrm{f}}\right]$, although a significant shift in answer distribution in participating men $(\mathrm{P}<0.0001)$ when comparing questionnaire Group $\mathrm{p}_{\mathrm{n}}$ and Group $_{\mathrm{m}, \mathrm{f}}$ with a lower rate of preferred male urologists (34.7\% vs. $54.5 \%$ ), fewer comments $(0.0 \%$ vs. $22.2 \%)$ and answer boxes left blank $(3.1 \%$ vs. $21.2 \%)$ when the answer 'no preference' was available (Figure 1). The same was true for the answers given by partners $(\mathrm{P}<0.0001)$. 'No preference' was chosen by $60.8 \%$ of patients and $57.3 \%$ of partners if available $\left(\right.$ Group $\left._{n \mathrm{p}}\right)$. One patient wanted to be seen by a female urologist in Group ${ }_{n p}$, and two patients in Group $p_{\mathrm{m}, \mathrm{f}}$. While answers on other questions were left blank only very rarely, the answer regarding the preferred gender of the urologist was left blank in $21.2 \%$ in Group m,f $_{\text {f }}$ Twenty-two percent of patients commented on the question instead of ticking the answer boxes ticking and wrote comments such as "I don't have a preference", "Capability is not a question of gender", "It doesn't matter, as long as she or he is capable".

\section{Cofactors influencing the male urologist preference}

A significant, yet small impact on male preference across both questionnaires was found regarding the marriage duration, i.e., the longer the marriage the more men chose male urologists $(\mathrm{B}=0.032, \mathrm{P}=0.019)$. The strongest predictor was the questionnaire type with Group $_{\mathrm{m}, \mathrm{f}}$ exhibiting a B-value of -0.813 (95\% CI: -1.490 to -0.278 , $\mathrm{P}=0.016)$. No other predictor, such as the number of prior prostate MRIs or prostate biopsies as a surrogate for previous contact with the urology profession, was found to be of significant impact (please refer to Table 1 for further details). 
Table 1 Factors influencing male urologist preference

\begin{tabular}{|c|c|c|c|c|c|}
\hline Factors & $\mathrm{B}$ & Bias & $P$ value & \multicolumn{2}{|c|}{$\mathrm{BCa} 95 \% \mathrm{Cl}$} \\
\hline Questionnaire, Group $\mathrm{m}_{\mathrm{m}, \mathrm{f}}$ & -0.813 & -0.059 & 0.016 & -1.490 & -0.278 \\
\hline Age & 0.007 & 0.002 & 0.818 & -0.064 & 0.085 \\
\hline Married & 0.53 & 0.061 & 0.238 & -0.491 & 1.740 \\
\hline Educational level: compulsory level ${ }^{\star}$ & 0.404 & 0.065 & 0.478 & -0.881 & 1.849 \\
\hline Educational level: craftsman* & 0.197 & 0.024 & 0.620 & -0.696 & 1.154 \\
\hline Retired & 0.394 & 0.018 & 0.419 & -0.647 & 1.497 \\
\hline Prior biopsies (n) & -0.147 & -0.063 & 0.312 & -0.565 & 0.032 \\
\hline Religion: Protestant ${ }^{\$}$ & -0.309 & -0.737 & 0.647 & -21.017 & 1.656 \\
\hline Planned examination: MRI & -0.21 & -0.005 & 0.557 & -0.985 & 0.534 \\
\hline
\end{tabular}

*, compared to 'no formal education'; $\$$, compared to 'no religious affiliation', frequency of Muslims too low for analysis. BCa, biascorrected accelerated; $\mathrm{Cl}$, confidence interval.

\section{Discussion}

In the USA the number of female urologists increased from less than $2 \%$ in 1980 to $9.2 \%$ in 2018 (9) and the female workforce in urology is believed to multiply by 3.77 in the USA from 2020-2040 (10). Considering these statistics, this study aims to determine whether the thesis of the "unpopularity of female urologists" (7) is still true. This study examines gender preferences among patients with prostate disease. In addition, we also examined if the patient's wives have gender preferences for their husbands' urologist.

The study was carried out in Austria, which is ranked $13^{\text {th }}$ in the European Union, according to the latest Gender Equality Index (11), which reflects the average of European countries. We therefore believe that our results are applicable to other highly developed western countries.

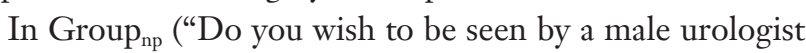
or a female urologist or no preference?") the majority of patients $(60.8 \%)$ chose the "no preference" answer. One patient wanted to be seen by a female urologist. $35 \%$ wanted to be seen by a male urologist. Tempest et al. conducted a study in 2005 and asked patients in a urology clinic in England about the preference of gender of the urologist. The found out that $83 \%$ of male urologic patients had no preference and only $17 \%$ preferred a male urologist (12).
As in our study they did not find that age or previous contact with the urology profession influenced gender preference.

In Group $_{\mathrm{m}, \mathrm{f}}$ ("Do you wish to be seen by a male urologist or a female urologist?") only $2(2 \%)$ patients wanted to be seen by a female urologist. $22 \%$ of patients commented on the question instead of ticking the answer boxes and wrote comments such as "I don't have a preference". In Group $_{\mathrm{m}, \mathrm{f}} 21 \%$ of patients did not answer the question. This is a considerable difference to Group ${ }_{n p}$, where only $3 \%$ of patients did not answer the question. We therefore assume that patients in Group $\mathrm{m}_{\mathrm{m}, \mathrm{f}}$ left it blank intentionally, especially when no other questions were left blank. Overall $43 \%$ of all patients in Group $\mathrm{m}_{\mathrm{f}} \mathrm{did}$ not answer the question on the preferred gender of the urologist, which makes us believe that they missed the answer option "no preference". However, the majority of patients in $\operatorname{Group}_{\mathrm{m}, \mathrm{f}}(54.5 \%)$ wanted to be seen by a male urologist.

It is of notice that there is no relevant difference between Group $_{\mathrm{m}, \mathrm{f}}$ and Group $\mathrm{p}_{\mathrm{np}}$ in the number of patients that want to be seen by a female urologist. This might suggest that many of the "no preference" answers in Group ${ }_{n p}$ may represent "male urologist" answers. Other studies, too, found that only very few patients wanted to be seen by a urologist of the opposite gender ranging from $1 \%$ to $3 \%(12,13)$. 
In our study the number of patients who prefer a male urologist is lower than previously reported by an Israeli study were $42.8 \%$ had a preference for a male urologist and $53.8 \%$ had no preference (12). This discrepancy to our results might be explained by the different cultural backgrounds and the time of publication of the study. Our findings suggest that the doctor's gender is more important to urologic patients than to other patients. A study comparing gender preferences among emergency room patients found that $89.5 \%$ do not have a gender preference (14). Among patients in orthopedic surgery, $78 \%$ do not have a preference for the gender of the surgeon (15). This is in line with a recent study from Saudi Arabia which found that $67.5 \%$ of men prefer a male physician for a genital examination but only $37.4 \%$ of men prefer a male doctor when discussing family problems (16). The answers of the partners in Group did not differ significantly from those of the patients. None of the partners wanted their husbands to be seen by a female urologist. Also in Group $\mathrm{p}_{\mathrm{m}, \mathrm{f}}$ the answers of the patients' partners did not differ significantly from those of the patients. $57 \%$ of the partners wished for a male urologist and only one woman wanted her husband to be seen by a female urologist. Of course, women are subject to gender stereotypes as well as men. It is also known that female patients prefer same gender urologist. This could be a reason why women wanted a male urologist for their partner. A Korean study found that $53 \%$ of Korean women prefer female urologists and only $36.4 \%$ had no gender preference (17). In Group $\mathrm{m}_{\mathrm{m}, \mathrm{f}}$ slightly more women wanted their partner to be seen by a male urologist than the men themselves. Some authors believe, that the issue of the doctor's gender is more important for women (18). It might be that women assume that the gender of the urologist has the same importance for the husbands as for them. Unfortunately, we were not able to evaluate other possible factors for the partners' choice, such as jealousy.

We examined causes that might influence the choice of gender. We did not find that the level of education, profession, age, religion nor previous contact with the urologic profession (represented by the numbers of previous biopsies) had a significant influence on gender preferences. Longer marriage duration was associated with a preference for a male urologist, though. Our results differ from Amir et al. (2018), who reported that patients preferring male urologists where more religious and married (19). In our study the most significant impact on gender preference was the type of questionnaire and therefor the options for answering the patients received (Group ${ }_{n p}$ or Group $_{\mathrm{m}, \mathrm{f}}$ ).

Although our study gives an important insight on the acceptance of female urologists, there are some limitations to report. As the gender-specific questions were asked among prostate related questions, we were not able to ask for the motivation for the choice of gender. The average age of the patients was 65.6 years, which is a typical age for prostate patients. Therefore, our study does not allow drawing conclusions on the preferences of younger patients. We only sent questionnaires to patients prior to prostate biopsies or prostate MRI. We therefore do not know if patients with other urologic problems would have answered in the same way. Although the patients and their partners were asked to fill in the questionnaires separately, we were not able to ensure that they did not compare their answers prior to submitting the questionnaires. This is a single center survey, which may reduce the generalizability.

Our data does not show a general "unpopularity of female urologists" as claimed in the 1960s, but it shows that a large number of patients with suspicion of prostate disease prefer a male urologist.

\section{Conclusions}

We conclude that a large number of male patients with suspicion of prostate disease and their partners still prefer male urologists when hard-pressed on a choice between a male or female doctor. Considering the growing number of practicing female urologists, we should strive to increase acceptance of female urologists so that the doctor's gender becomes less of an issue for urologic patients.

\section{Acknowledgments}

Funding: None.

\section{Footnote}

Reporting Checklist: The authors have completed the SURGE reporting checklist. Available at https://dx.doi. org/10.21037/tau-21-131

Data Sharing Statement: available at https://dx.doi. org/10.21037/tau-21-131

Peer Review File: Available at https://dx.doi.org/10.21037/ tau-21-131 
Conflicts of Interest: All authors have completed the ICMJE uniform disclosure form (available at https://dx.doi. org/10.21037/tau-21-131). The authors have no conflicts of interest to declare.

Etbical Statement: The authors are accountable for all aspects of the work in ensuring that questions related to the accuracy or integrity of any part of the work are appropriately investigated and resolved. The study was conducted in accordance with the Declaration of Helsinki (as revised in 2013). The study was approved by institutions local ethics committee Innsbruck Medical University (NO.: EK-Nr. 1162/2017) and informed consent was taken from all individual participants.

Open Access Statement: This is an Open Access article distributed in accordance with the Creative Commons Attribution-NonCommercial-NoDerivs 4.0 International License (CC BY-NC-ND 4.0), which permits the noncommercial replication and distribution of the article with the strict proviso that no changes or edits are made and the original work is properly cited (including links to both the formal publication through the relevant DOI and the license). See: https://creativecommons.org/licenses/by-nc-nd/4.0/.

\section{References}

1. Hibbeler B, Korzilius H. Arztberuf: Die Medizin wird weiblich. Dtsch Arztebl International 2008;105:A-609/ B-539/C-527.

2. Jolliff L, Leadley J, Coakley E, et al. Women in U.S. Academic Medicine and Science: Statistics and Benchmarking Report 2011-2012. Association of American Medical Colleges, 2012.

3. Riepen T, Mobus V, Kullmer U, et al. Male and Female Physicians in Hospital Gynaecology Departments - Analysis of the Impact of "Feminisation" from the Viewpoint of Medical Directors. Geburtshilfe Frauenheilkd 2013;73:53-8.

4. Halpern JA, Lee UJ, Wolff EM, et al. Women in Urology Residency, 1978-2013: A Critical Look at Gender Representation in Our Specialty. Urology 2016;92:20-5.

5. Schmittdiel J, Grumbach K, Selby JV, et al. Effect of physician and patient gender concordance on patient satisfaction and preventive care practices. J Gen Intern Med 2000;15:761-9.

6. Rizk DE, El-Zubeir MA, Al-Dhaheri AM, et al. Determinants of women's choice of their obstetrician and gynecologist provider in the UAE. Acta Obstet Gynecol Scand 2005;84:48-53.

7. Phelps CE. Women in American medicine. J Med Educ 1968;43:916-24.

8. Obermann K, Woerns S. Ärzte im Zukunftsmarkt Gesundheit 2018 Gender in der ambulanten Medizin: Die Wahrnehmung der Leistungen von Ärztinnen und die demographische Entwicklung: Stiftung Gesundheit, 2018.

9. Velez D, Ashok A, Greenberg R, et al. Rising Tides: Challenges and Opportunities for Women in the Urologic Workforce. Urology 2021;150:47-53.

10. Nam CS, Daignault-Newton S, Herrel LA, et al. The Future is Female: Urology Workforce Projection From 2020 to 2060. Urology 2021;150:30-4.

11. Barbieri D, Janeckova H, Janeckova H, et al. Gender Equality Index 2017 Measuring gender equality in the European Union 2005-2015 European Institute for Gender Equality, 2017.

12. Tempest HV, Vowler S, Simpson A. Patients' preference for gender of urologist. Int J Clin Pract 2005;59:526-8.

13. Ficko Z, Li Z, Hyams ES. Urology is a Sensitive Area: Assessing Patient Preferences for Male or Female Urologists. Urology Practice 2018;5:139-42.

14. Nolen HA, Moore JX, Rodgers JB, et al. Patient Preference for Physician Gender in the Emergency Department. Yale J Biol Med 2016;89:131-42.

15. Abghari MS, Takemoto R, Sadiq A, et al. Patient perceptions and preferences when choosing an orthopaedic surgeon. Iowa Orthop J 2014;34:204-8.

16. Alyahya G, Almohanna H, Alyahya A, et al. Does physicians' gender have any influence on patients' choice of their treating physicians? J Nat Sci Med 2019;2:29-34.

17. Kim SO, Kang TW, Kwon D. Gender Preferences for Urologists: Women Prefer Female Urologists. Urol J 2017;14:3018-22.

18. Derose KP, Hays RD, McCaffrey DF, et al. Does physician gender affect satisfaction of men and women visiting the emergency department? J Gen Intern Med 2001;16:218-26.

19. Amir H, Beri A, Yechiely R, et al. Do Urology Male Patients Prefer Same-Gender Urologist? Am J Mens Health 2018;12:1379-83.

Cite this article as: Steinkohl F, Luger AK, Gruber L, Hochleitner M, Pichler R, Heidegger-Pircher I, Bektic J, Aigner F. Acceptance of female urologists among patients with suspected prostate disease. Transl Androl Urol 2021;10(7):29382943. doi: $10.21037 /$ tau-21-131 